\title{
LATINISMOS DEL ACTO DE ESCRIBIR SERMO LATINUS IN SCRIBENDI ACTU
}

\author{
Latinisms in the act of wrinting \\ Sermo latinus in scribendi actu
}

Manuel Antonio Quirós Rodríguez ${ }^{\dagger}$

\begin{abstract}
RESUMEN
El latín les ha suministrado a las lenguas romances y germánicas el alfabeto, la escritura y ha sido usual que las haya dotado de cultismos y latinismos: una gran cantidad de abreviaturas, siglas, símbolos, palabras, sintagmas, frases y oraciones, empleados, en el mismo latín, durante el proceso de escritura de las lenguas modernas. El autor presenta un glosario con muchos latinismos, los cuales serán útiles en el acto de escribir en un plano universal.

Palabras clave: escritura, glosario, latín, latinismos, lenguas modernas.
\end{abstract}

\begin{abstract}
Latin is an international language through time and in many geographic places. It has supplied the modern western languages the alphabet, with writing and learned words. There are many abbreviations, words, phrases, sentences and a few symbols, all of which are used in the same Latin and in the Modern Languages during the process of texts writing. Enough examples, which will be useful during the writing act in some of the modern languages of Western Civilization are hereby showed by the author of this paper.
\end{abstract}

Key Words: Writing, Dictionary, Glossary, Latin, Modern Languages. 


\section{Palabras, sintagmas y frases en el acto de escribir}

Esta presentación gira sobre el actus scribendi, o mejor, el ars scribendi, dado que escribir entra en la categoría de arte $<$ del latín artus, estrecho, debido a las estrechas reglas del arte, una actividad intelectual, la cual requiere un serie de conocimientos en la elocutio, (gramática y estilo), además de ciertas habilidades, apoyadas mediante lecturas y de la misma escritura.

En el acto de la escritura, el uso del latín se mantiene mediante el préstamo de palabras, sintagmas, frases, locuciones y oraciones.

Los romanos, debido a sus contactos con Grecia, se iniciaron en el arte de la escritura, incluso, literaria, mediante la imitación y emulación.

El arte de escribir en lengua latina continuó durante toda la Edad Media, y, en un cierto momento, los clérigos, la gente culta que sabía y escribía latín, comenzó a escribir en su idioma nacional, lo cual ha ocasionado que el latín haya estado presente, desde entonces, en las lenguas romances, incluso, las germánicas, de tres maneras:

\section{Mediante palabras populares o} patrimoniales: voces que han pasado directamente a cada uno de los romances y se han desarrollado de acuerdo con las características generales de todos ellos, de un grupo de éstos o, en cada uno, conforme a las particularidades detectadas por la gramática histórica. Según el profesor salmantino, Gregorio Hinojo Andrés:

La mayor procedencia de tales palabras proviene del latín y han heredado de este tanto la significación propia como la figurada.

2 Mediante cultismos: palabras casi iguales, en su contextura, al latín, pero mínimamente adaptadas, a los romances, de modo que estas sean lenguas neolatinas y no latín.
$3 \quad$ Mediante latinismos: palabras y formas netamente latinas, que en han ingresado y sobrevivido en las lenguas actuales.

Los verbos: castellano, escribir; italiano, scrivere; portugués, escrever; rumano, scrie; francés, écrire; alemán, Schreiben; inglés, to write, neerlandés, schrijven; sueco, skriva se remontan al respectivo verbo latino scribere, correspondiente al gr. graféin uno de los actos esenciales propio del homo sapiens; por consiguiente, esencia del "Humanismo".

Scribere y graféin, además de la acepción fundamental de escribir, significan: hendir, agrietar, rasgar, aruñar, rasguñar, poner marcas y símbolos de cuando se comenzaron a trazar letras sobre tablillas enceradas, lo cual consistía en hendir y agrietar la tablilla provista de cera para arrancarle letras, palabras y oraciones por medio del estilete. Luego, el verbo amplió su significado al acto de escribir en general mediante cualquier material, incluso, electrónico. De scribo, scripsi, scriptum, scribere proviene scriptura, un cultismo, como participio futuro de tal verbo, con e-protética de apoyo. De haber sido una vez popular, habría dado "escredora", lo cual demuestra cómo, en el estudio de la gramática histórica, por ejemplo, del castellano, se ha tomar en cuenta la latinidad total y no solo la vulgar.

Como voy a tomar en consideración algunos latinismos, aunque varios de ellos carezcan de contenido semántico, por tratarse de partículas, a saber, artículos, adverbios, conjunciones y preposiciones, junto con otras consideraciones, recalco lo que es un latinismo

Un latinismo consiste en la aceptación y empleo, en una lengua nacional, sea neolatina o no, de una:

sigla, abreviatura, prefijo, palabra, nombre, sintagma, definición, alfabeto latino, escritura romana, número romano, frase, giro, máxima, proverbio, sentencia, dicho, adagio, refrán, locución, expresión, fórmula, inscripción, afirmación, consejo, cita, título, lema, marca de fábrica, frase, oración, unidades univerbales y 
pluriverbales tomados directamente del latín y preservados como tales.

De las palabras anteriores, solo defino el "sintagma" debido a su difícil comprensión a pesar de lo mucho que se usa:

sintagma < syntágma: composición, disposición, ordenamiento, organización. Grupo de un mismo enunciado idiomático conformado por dos o más signos lingüísticos (conjunto de palabras) en una relación sintáctica unitaria en la estructura de la frase.

El sintagma más comúnmente usado es la unión de un adjetivo con un sustantivo, y es la más importante figura de acumulación. En retórica, un sintagma es cualquier adjetivo o frase adjetival (epithetum ornans) que se adjunta a un sustantivo para dotarlo de ciertas cualidades: vigor, caracterización, descripción, colorido, esplendor en forma exacta, gráfica y sugerente. Es todo un ornatus, fioritura del sustantivo, para que éste se destaque estilísticamente.

No es lo mismo casa / bella que casa bella.

Algunos sintagmas en latín, en su respectiva traducción, son los siguientes:

Aurea mediocritas, la dorada medianía, el término medio; ars sacra, el arte sagrado; ars gratia artis, el arte por el arte; urbs Aeterna, la ciudad eterna; locus amoenus, sitio agradable; homo sapiens, el hombre sabio; sermo quotidianus, latín vulgar; sermo perpolitus, latín clásico.

Garcilaso hace uso de epítetos y sustantivos como herencia de la poesía grecolatina en relación con el tópico de la Natura:

Convida a dulce sueño

aquel manso ruido

el agua que la clara fuente envía.

$Y$ las aves sin dueño

con canto no aprendido

hinchen el aire de dulce armonía;

háceles compañía

a la sombra volando

$y$ entre varios olores

gustando tiernas flores

la solícita abeja susurrando.

\section{Deslinde del cultismo / latinismo}

Principalmente, en las lenguas romances, por proceder, en modo directo, del latín, no siempre resulta difícil diferenciar el cultismo del latinismo, por ejemplo: fabula, forma prosa, rosa.

cultismo Con este nombre...se designa todas aquellas palabras que han entrado en un idioma en épocas diversas por exigencias de cultura (literatura, ciencia, filosofía, etc.) procedentes del registro culto del latín. Tales voces mantienen su forma latina, sin haber sufrido las transformaciones normales como en las voces populares: fructífero, benévolo, colocar, etc."

El mismo punto de vista es sostenido por Carlo Tagliavini, en Orígenes...(1973:439-440) y por Rafael Lapesa, en Historia...(270):

El cultismo es un préstamo del latín a una o a varias lenguas modernas, no necesariamente romances, cuya simbiosis se efectuó con un mínimo de cambio lingüístico en la lengua prestataria; no así el latinismo: una apropiación directa de una palabra (préstamo léxico en significado y significante) frase $u$ oración del latín culto, y naturalmente, del clásico. En la consideración, pues, de los cultismos se han de tomar en cuenta las lenguas prestatarias: español, francés, italiano, inglés, alemán... No así en la consideración de los latinismos: aquí únicamente cuenta el puro latín.

latinismo Vocablo, sintagma o giro que conserva su forma exacta latina y ha sido introducido por influencia culta: maximum, minimum, minuscula, memorandum, curriculum vitae, alma mater, honoris causa, in extremis, lapsus calami, lapsus linguae, saecula saeculorum.

En cambio, en las mismas lenguas romances, la voz popular es la palabra procedente del latín vulgar con los cambios histórico-lingüísticos inherentes de su inicio y de conformidad con la evolución propia de cada romance, según se encuentra definido y ejemplificado en el libro, El latín y las lenguas romances (2000: 288). 


\section{Características del latinismo}

siguiente:

Un latinismo se caracteriza por lo

Procedencia directa, o indirecta, de cualesquiera de los subcódigos escritos del latín culto: clásico, medieval, renacentista, bíblico-cristiano, eclesiástico litúrgico... Introducción por vía letrada, visual (literatura, derecho...) desde algún libro, o por el estudio y conocimiento del latín.

Vía, casi siempre, mediante instituciones académicas y libros.

Penetración en el transcurso de diversos períodos histórico-culturales.

Internacionalidad y universalidad: es común que algún latinismo haya penetrado en distintas lenguas modernas, incluso, en varias.

En ciertos casos, anonimato, pues se desconoce quién lo haya elaborado y en qué circunstancia haya sido aceptado por alguna lengua.

Monosemia, particularmente, en el campo de las ciencias exactas: un término con un significado preciso, para que no haya ambigüedad.

Invariabilidad, pues no opera el cambio lingüístico, en parten causante de la transformación del latín vulgar en romance.

Diferenciación del cultismo, el cual se amolda, mínimamente, a las características de la respectiva lengua nacional.

\section{Clasificación de los latinismos}

Los latinismos pueden ser clasificados de la siguiente manera:

Léxicos: palabras simples.

Morfológicos y sintácticos: expresiones pluriverbales.

Por procedencia del subcódigo: latín clásico, latín medieval, latín humanista-renacentista, latín cristianoeclesiástico-litúrgico, latín jurídico, latín científico...

Por disciplinas académicas: filosofía, teología, historia, derecho, letras: filología: gramática, literatura; artes, ciencias....

Forma de aparición: palabra, inscripción, letrero, lema, máxima, adagio, sentencia, aforismo...

Épocas de entrada: cualquiera, especialmente, durante los distintos renacimientos, y a partir del siglo XVIII: neologismos científicos y técnicos.

\section{Vías de penetración y uso de los latinismos}

Reitero siguientes actividades, y por tanto, las vías de penetración, principalmente, académicas, en donde entran en juego los latinismos:

El legado clásico en todas las épocas, sobre todo, en cada uno de los renacimientos: el Renacimiento Carolingio, el Renacimiento del Siglo XII, el Gran Renacimiento, originado en el Humanismo.

La enseñanza del latín, desde el Tardío Imperio Romano en instituciones docentes, especialmente, universidades, en cuyo origen medieval, era idioma oficial e internacional como continuación del latín culto; un subcódigo de cultura del Occidente con una larga y tradición universal.

Historia: época clásica, época de Constantino, la Hispania visigótica, el Humanismo-Renacimiento, las universidades en su origen.

La Iglesia Católica Romana, que ha adoptado el latín como idioma oficial por razones históricas y prácticas, con su lenguaje bíblico y cristiano y el medio eclesiástico-litúrgico. Muchas gente ha escuchado y hasta sabe de memoria los nombres de las partes de la misa, incluso, este es un nombre latino: ite, missa est, Magnificat, Te Deum, vulgata, consilium, pax romana, diez irae.

El estudio de la gramática y literatura del latín. Medios de escritura: códices, incunables, libros, mecánicos, electrónicos.

Letras: filología, lingüística, gramática, literatura.

Artes: música, arquitectura, escultura, pintura.

Filosofía, teología.

Derecho Romano: iux y lex

Ciencias, sobre todo, naturales: química, botánica, zoología, medicina alopática y homeopática.

Lenguaje simbólico. 
Lenguaje bíblico y cristiano.

El medio eclesiástico-litúrgico.

\section{Adstrato cultural latino}

Lo anteriormente considerado integra el sintagma/concepto de adstrato cultural latino, según el cual el latinismo ha ingresado, en las lenguas modernas, por vía culta, y no como el latín vulgar, el hablado, el cual existe desde que existe el mismo latín y se ha expandido por la fuerza de las armas, y, natural y espontáneamente, ha dado origen a las lenguas neolatinas por causa, entre otras, del cambio lingüístico.

Carlo Tagliavini (1981: 463) expresa:

\begin{abstract}
Hay un superestrato que afecta a todas las lenguas romances occidentales, no debido a conquista y a ocupación territorial, como pasa con el germánico o el árabe, sino siempre y por doquier de carácter más o menos erudito: es el cultural latino"... ...”aún después de la caída del Imperio Romano de Occidente, después de las invasiones bárbaras y de la constitución de nuevos reinos e imperios, el latín no se extinguió, nunca dejó de servir como lengua literaria y cultural, jurídica y notarial. No sólo lo mantenía vivo el prestigio de la Roma antigua, de la capital del mundo civil, sino el hecho importantísimo de haberse vuelto el latín, en Occidente, la lengua oficial de aquella religión cristiana que se difundía velozmente por doquier y que tenía su centro en Roma, de aquella Iglesia que era católica, es decir, universal pero también romana.
\end{abstract}

Santiago Segura Munguía (1977: 280) acota que a lo anterior contribuyó, en gran medida, el eximio escritor de la latinitas (latín clásico), Marco Tulio Cicerón:

...Cicerón, por tanto, debió crear un lenguaje filosófico y científico, un vocabulario del pensamiento, el mismo que hoy es la base de la ciencia del Occidente, ya que sus creaciones lingüísticas pasaron a las lenguas románicas literarias e incluso a la lengua hablada....

Tanto las lenguas romances como las germánicas comienzan a ser escritas más o menos por los siglos VIII y IX X, luego de la desaparición del Renacimiento Carolingio, cuando las autoridades eclesiásticas se dan cuenta de lo inútil que significa predicar el Evangelio en latín a gente iletrada, desconocedora del latín y van al encuentro del naciente romance para que se escriba en éste y en germánico, puesto que eso tiene lugar en la confluencia de regiones románicas con regiones germánicas.

\section{Las glosas y el glosario}

Dentro de las maneras de registrar un repertorio de palabras, se encuentra el glosario, el cual es un diccionario en pequeño sobre una materia en particular, con sus dos partes constitutivas fundamentales, como se verá. Consiste en repertorio onomasiológicolexicográfico.

Las glosas y los glosarios han desempeñado, desde los griegos hasta el Renacimiento, un importante papel como precursores de los modernos diccionarios, con la finalidad de aclarar y explicar palabras supuestamente incomprensibles para los lectores del texto base.

Una glosa consta del lemma, parte por explicarse, en este caso, el latinismo: lengua fuente, y el interpretamentum: traducción, aclaración, definición y hasta comentario crítico sobre el lemma para explicarlo en la lengua destino, en el presente caso, castellano.

Un glosario, pues, es un conjunto de glosas: palabras o frases yuxtapuestas a otras palabras o frases desconocidas para explicarlas y hacerlas comprensibles.

\section{Método del presente glosario}

Abordo este repertorio terminológico mediante una de las ramas de la lexicografía teórica, la metalexicografía: el arte de elaborar diccionarios, en mi caso, un glosario, aunque no siga todas la pautas en el empleo de todos sus constituyentes y símbolos; un "glosario" con su lemma: entrada enunciativa del artículo, todas las cuales corresponden a lo que se conoce como "nomenclatura", ésta, explicada mediante el interpretamentum: rema o entrada informativa. 
El método consiste en proceder justo como en la confección de las glosas lingüísticas: recolección y registro de una determinada cantidad de latinismos y su explicación mediante una traducción, un sinónimo, una definición sobre aspectos filosóficos, artísticos, filológicos,...: una etimología comentada, una rápida explicación histórica y cultural, un breve análisis gramatical, un comentario crítico de interés contextual, una simple clasificación o división: gramática..., un articulito, una noticia bibliográfica de interés, todos los cuales como aclaraciones subsiguientes o como yuxtaposición al latinismo.

En otras presentaciones, yo mismo cité el método, que ahora explico un poco más:

Cada grupo de lemas aparece con la respectiva letra del orden alfabético con mayor tamaño y en negrita

La labor consiste, en parte, en un "glosario": un lemma: entrada enunciativa del artículo, todas las cuales corresponden a lo que se conoce como "nomenclatura", ésta, explicada mediante el interpretamentum: rema o entrada informativa de acuerdo con un

orden alfabético, por lo cual se pierde la secuencia temática, precedido por el respectivo grafema: la primera palabra, la enunciativa o tema inicial del glosario, escrita en letra negrita minúscula, aunque sea un nombre propio, consiste en la palabra, sintagma, frase, incluso, algunas que otra oración de ser explicados y comentados por en el interpretamentum, rema, elemento informativo.

La exposición, en orden alfabético, excluye cualquier otro orden: por categorías gramaticales o por palabras o partículas ya sean solas o acompañadas de otras partículas. En muchos cosas, si es factible, el lemma es extraído de vocablos de la retórica de los antiguos grecorromanos.

El interpretamentum está explicado de dos maneras: 1) luego de dos puntos, la palabra textual en espacio simple y con letras cursivas en idioma español. 2) Después, siguen, algunas veces, pequeñas explicaciones o comentarios, de los cuales constituyen también parte integrante el destinatario, el lugar y la fecha de escritura.

El interpretamentum está dividido en dos: 1) luego de dos puntos, la palabra textual en espacio simple y con letras cursivas en idioma español. 2) Después, siguen, algunas veces, pequeñas explicaciones o comentarios, de los cuales constituyen también parte integrante el destinatario, el lugar y la fecha de escritura.

\section{Repertorio lexicográfico}

Como expresé, muchos de los latinismos del repertorio lexicográfico, de uso en el arte de escribir, está conformado por partículas sin ningún contenido semántico, pues son adverbios, preposiciones, o locuciones conformadas por ambas; por lo cual, durante mi exposición, he de hacer una selección coherente mediante la presentación de los latinismos más usados y sin recurrir mucho a siglas y partículas sin contenido semántico. Prefiero recurrir a frases y oraciones que posean relación con el actus scribendi.

\section{A}

ab initio (ab. Init.) Desde el principio.

ab integro Íntegramente.

ab Urbe condita (ab U. c. $)=$ Anno post Romam conditam (a.p.R. c.) Desde la fundación de Roma. Cómputo de los años hasta el siglo VIII.

acta Hechos, acciones, actos, leyes, ordenanzas, decretos. En español, acta es masculino, pero proviene del neutro plural. El verbo es ago, agis, actum, agere, hacer, actuar. Acto, una de las partes fundamentales de una obra teatral o de una ópera. La palaba es un cultismo, porque no sigue la evolución normal y repetitiva de determinada lengua romance.

acta est fabula Fin de la representación de una obra teatral

actus ut supra Sucedido como arriba (sucedió). Formula final en protocolos legales. 
adde Agregue.

addenda et corrigenda Lo que debe ser agregado y corregido. Verbos en gerundivo, neutro plural, voz pasiva.

addendum Lo que debe agregarse; agregado, apéndice. Verbo en gerundivo de voz pasiva singular. El verbo latino es addo, -is, addidi, additum, addere.

addidit, addunt (add.) Agregó, agregan.

ad hoc Para esto, para tal propósito especial. Referencia a una situación particular con un fin determinado. Hoc es el acusativo masculino del pronombre personal hic, haec hoc, éste, ésta, esto.

ad idem Para lo mismo. Con el mismo efecto. En latín, el neutro singular de isdem, eadem, idem, lo mismo.

\section{ad infinitum Infinitamente.}

ad interim Interinamente. El vicepresidente ocupó la presidencia ad interim, por un determinado tiempo, temporalmente.

ad kalendas graecas En las calendas griegas = nunca, pues los griegos no tenían "calendas", el primer día del mes. Calare, llamar, convocar, proclamar, como en calata comitia, asamblea a la que se convocaba el pueblo para la elección de los flámines y otras deliberaciones religiosas". (Segura Munguía. Diccionario: 87).

ad libitum (ad lib.) A gusto, a voluntad. Por ejemplo, interpretar un pasaje musical a gusto del ejecutante; ad libitun Caesarum, a voluntad de los césares. El verbo en latín es libet.

ad litteram A la letra, literalmente. Por ejemplo, la cita de un autor sin ningún cambio.

De littera, letra, se deriva literatura. Littera traduce la palabra griega gramma, letra, y de gramma, se deriva ars / grammatica, gramática.

ad locum (ad loc.) Hacia el lugar.

ad multos annos Por muchos años.

ad notam, nota bene Observaciones.

ad pedem litterae $\mathrm{Al}$ pie de la letra.

ad perpetuam rei memoriam Para perpetua memoria. ad quem Por ejemplo, en la expresión terminus ad quem, en contraposición a terminus a quo.

ad rem $\mathrm{Al}$ asunto. Por ejemplo, responder en el punto preciso, sin ambages.

ad valorem ( $a d v a l$.) De acuerdo con el valor.

ad referéndum Fórmula cancilleresca. Mandar a consideración para aprobar algo escrito. El verbo latino es un compuesto de: re-fero, refers, retuli, relatum, referre. Del supino relatum, viene el cultismo "relato" y del infinitivo referre, referir con cambio de conjugación en español.

ad usum (ad us.) Según el uso.

ad usum Delphini. Para el uso del Delfín. Son ediciones de los clásicos revisadas y expurgadas de pasajes obscenos para que las pudiera leer el hijo de Luis XIV, Le Grand Dauphin. En francés es Dauphin, del latín delphinus, título del primogénito y heredero de la Corona del rey de Francia, adoptado en 1340 como consecuencia de la cesión del Delfinado (Viena y Alvernia) a la Casa Real de Francia.

agenda Lo que debe ser hecho o llevado. El orden del día en una reunión: asuntos de ser tratados según un orden determinado. Participio futuro, voz pasiva, neutro plural del verbo ago, egi, actum, agere, hacer, actuar, llevar.

album Blanco, lo blanco. Entre los romanos, el album era una tabla de madera blanqueada usada por los sacerdotes, miembros del senado y otras autoridades para suministrar informaciones. En Grecia, correspondía a los $\lambda \varepsilon v \kappa о \mu \alpha$. Actualmente, es un libro o cuaderno dejado sin escritura ni dibujos para pegar objetos, como fotografías. En latín, existe el sust. album, $-i$, y el ad. albus, - a, -um. Album es a niger como candidus a ater.

alea iacta est La suerte está echada. Decisión del general romano, Cayo Julio César para dirigirse hacia Roma y constituirse en dictado, lo cual no le fue conseguido, pues fue asesinado en el Senado mismo

alias De otro modo, con otro nombre. Por ejemplo, alguien se llama Francisco, alias, Paco o Pancho, pues Francisco es conocido también por tales hipocorísticos. 
alma mater Madre nutricia. Alma, alma, anima; nutricia; el verbo es alere, alimentar, de donde alumno, el alimentado, metafóricamente, por el profesor

alii (al.) Otros.

anni currentis (a. c.) Del año en curso.

anno Domini (a. D.) En el año del Señor. Se emplea, sobre todo, en idioma inglés, para indicar una fecha a partir del año de nacimiento de Jesucristo. En la Inglaterra medieval, Beda el Venerable (672-735), el mejor escritor de literatura latina de su país, es autor de la Historia ecclesiastica gentis Anglorum, como expresa Santiago Prampolini (1955: 277), en donde, dio inicio el cómputo de los años a partir del nacimiento de Jesucristo, en sustitución de consulibus, siendo cónsules o el Ab urbe condita (desde la fundación de Roma, 23 de Abril del 723 A. C.)

anno Salutis (a. S.) En el año de la salud, salvación. Del nacimiento de Jesucristo.

anno Urbis conditae $=\mathbf{A b}$ Urbe condita. $A$ partir de la fundación de la Ciudad (Roma).

annos vixit (a.v.) Vivió tantos años.

ante Christum natum (a. Ch.n.) Antes del nacimiento de Jesucristo. Antes de la Era Cristiana.

ante meridiem (a. m.) Antes del medio día

aperto libro $A$ libro abierto. El sintagma hace referencia a un examen con el libro abierto, no de memoria, sino explicando y comentando su contenido. Ablativo.

apparatus criticus Aparato crítico. Texto de referencia usado en la ecdótica y en la docencia de textos latinos.

apud Ciceronem En Cicerón. En, entre, según Marco Tulio Cicerón. Apud Ciceronem legimus, hemos leído en Cicerón...

argumentum ab auctoritate Argumento basado sobre el principio de la autoridad.

ars bene scribendi El arte de escribir bien. No es otra cosa que el estilo, el cual se debe fundamentar sobre un buen conocimiento de la gramática.

ars dicendi Oratoria. El arte de convencer mediante la palabra oral siguiendo los principios de la retórica.

ars poetica El arte de la poesía o tratado de retórica poética.

artes liberales Algunos dicen que son las artes que se aprenden en los libros; o las artes que hacen al hombre libre.

artium Baccalaureus (a.b., A. B.) Bachiller en artes (y letras).

auctor ignotus Autor o escritor desconocido.

auctores Los (autores) clásicos. La palabra proviene del verbo augeo, -es, auxi, auctum, augere, aumentar, con la idea de que un "autor" le aumenta algo al caudal lingüístico de su idioma.

auctoritas Autoridad. El magisterio de los clásicos latinos, cuya significado se empleó, posteriormente, a cualquier magisterio, sobre todo, bíblico, papal y eclesiástico para reforzar, retóricamente, ciertas opiniones.

audio \& video Veo y oigo. Aparatos eléctricoelectrónicos de audición y visión.

aurea mediocritas La dorada medianía. Según Horacio, la moderación en todo, para que no se comentan errores ni por exceso ni por defecto.

\section{B}

bene probatus Aprobado con nota buena un examen.

bis Dos veces.

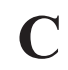

caetera quis nescit? (Ovidio). ¿Y lo restante quién lo sabe? Hay muchas cosas más que...

captatio benevolentiae Aceptación del favor del público, sobre todo, a favor de alguna obra artística, principalmente, literaria.

circa (C., ca.) Más o menos, alrededor, aproximadamente.

citatum Citado. 
codex Libro, códice.

conditio sine qua non...Condición para hacer tal o cual cosa

confer (cf.) Compárese, compare. Principalmente, en trabajos científicos. Imperativo del verbo confero, contuli, conlatum, conferre.

contraria contrariis curantur Lo contrario es sanado por lo contrario. Lema de la medicina, la cual se opone o es complementada por la medicina homeopática, cuyo lema es similia similibus curantur Lo semejante se cura con lo semejante.

corpus Cuerpo. Por ejemplo, el Corpus inscriptionum latinarum, que contiene todas o casi todas las inscripciones en latín.

curriculum vitae (c.v.). Carrera, percurso de vida, hoja de vida. Resumen de la labor académica y profesional de una persona.

cum laude Con alabanza. Aprobado con distinción en un examen universitario.

\section{D}

data Datos, fecha. Plural de datum, lo dado.

de facto De hecho.

de verbo ad (in) verbum Palabra por palabra. Manera de analizar e interpretar un párrafo o un texto, literalmente.

definiens Lo que define. En un glosario o diccionario, la parte que define.

definitus Lo definido.

de die in diem (de in d.) De día en día.

deo volente (D.v.) Si Dios quiere. Ablativo absoluto.

deus ex machina $U n$ dios desde alguna máquina. La intervención de alguna fuerza extraña para la solución de algún problema en una obra de teatro.

doctor (dr.) Doctor, Más sabio que... Comparativo de doctus. Máximo título académico otorgado por alguna universidad. Falsamente, por conveniencia, tal título se le otorga a cualquier profesional de alguna de las ramas de la salud

dono dedit (d.d.) Dado como regalo.

dorsum inclinat, costas in ventrem mergit et omne fastidium corporis nutrit. Se tiene la espalda inclinada ; a uno se le incrustan las costillas en el estómago, con lo cual alimentar todo el fastidio de su cuerpo. (Colofón del acto de escribir).

dramatis personae (Dram. Pers.) Personas del drama. Reparto de personas (actores) en una obra teatral u operística.

\section{$\mathbf{E}$}

eadem (idem) Lo mismo, las mismas cosas.

edidit Editó el libro.

eodem loco En el mismo lugar. En el mismo sitio, tratándose de un libro.

ergo Por lo tanto. Como manifestó el filósofo Descares, Cogito, ergo sum, pienso, luego existo.

errata Error, equivocación. En la impresión de un libro. El verbo es erro, -avi, erratum, -are.

$\boldsymbol{\&}<$ et, $y$. Realización de grafema medieval impreso en la escritura manual, mecanográfica, o computativa.

et alia $Y$ otras cosas.

et alibi $Y$ en cualquier parte o sitio.

et alii $Y$ otros. Libro escrito por determinado autor con el auxilio de otras personas, cuyos nombres no quedan citados.

et caetera, etcetera (etc., cet) Lo demás, lo restante. Procede de caeterus, - - , - - um, lo restante. Nominativo neutro plural.

et similia Y las cosas semejantes, lo semejante.

ex libris De los libros Por ejemplo, de los libros de Antonio, y sigue el nombre del poseedor (ex libris Antonii).

exegi monumentum aere perennius. Metáfora horaciana sobre su obra literaria más duradera que el bronce.

exordium, expositio, inscriptio Normas para redactar documentos que no son oficiales.... 
excerpta Selección.

excursus Digresión.

exequatur Ejecútese, ejecución. Forma imperativa tercera persona singular del verbo ex sequi.

editio (ed.) Edición.

exempli gratia, verbi gratia ( e. gr . o vg.) Por ejemplo.

explicit Lo escrito al final de un libro manuscrito expressis verbis Con palabras expresas, expresamente

et al. Et. alii o et aliae $Y$ otros, $u$ otras.

ex officio (e.o.) En virtud de su oficio o cargo.

et sequens (et. seq.) $Y$ lo siguiente.

et sequentes (et. seq.) $Y$ los que siguen, los siguientes.

\section{F}

flatus vocis Soplo de la voz. Según san Anselmo de Canterbury, aunque filósofo escolástico italiano, este sintagma expresa una palabra sin contenido semántico, pues es puro aire. expresa nada.

facta = data. haec epistula facta est... Esta carta fue hecha (fecha) a los tanos y tantos días...En idioma español, fecha se deriva de facta, hecha

factura (f.a) Latinismo contrapuesto a la voz popular "hechura".

factura pro forma Factura provisional.

$\mathbf{f a x}=\mathbf{f a c s}<\mathbf{f a c}$ simile Hazlo semejante. Máquina para enviar correos, anterior a la computadora e internet.

fec (fecit) Lo hizo.

fecerunt (ff) Lo hicieron.

hic iacet Aqui yace (sepultado)...

finis Fin. Se suele poner al final de un libro.

folium Folio (cultismo); hoja (voz popular, derivada de folia) folio recto (f.r.). La página de enfrente de un libro.

folio verso (f.v.). La página de atrás de un libro.

fortunae rota $L a$ rueda de la fortuna. Esta siempre está girando y nunca se sabe cuándo y a quién le toca, nam variabilis est, pues es variable. Fortunae rotam plango...Lloro las heridas de la fortuna, como rezan los Carmina Burana, poemas de clérigos medievales.

furor scribendi Arrebato, delirio, frenesí en el escribir, cuando un poeta se encuentra invadido por el estro.

\section{H}

habeas corpus ¡Que tengas el cuerpo (libre)! Interpretación: escrito legal de libertad provisional.

hic et ubique Aquí y en todas partes. Expresión que aparece en ciertos títulos universitarios, cuya emisión, generalmente, es de validez mundial.

historia, magistra vitae La Historia, maestra de la vida. ¡Si los políticos, sobre todo, los tiranos dictadores conocieran y apreciaran la historia y procedieran conforme, cuántos errores habrían evitado y evitarían!

historia teste Poniendo la historia como testigo. Ablativo absoluto

hoc anno (h.a.) En este año. Hoc es el ablativo masculino singular del pronombre demostrativo de hic, haec, hoc, este, esta, esto.

hoc est Esto es, es decir, a saber. En el mismo latín, no se usa, pues este idioma recurre a scilicet, videlicet.

hoc loco (h. l.) En este lugar.

hoc mense (h. m.) En este mes.

hoc sensu (h. s.) En este sentido.

hoc tempore (h.t.) En estos tiempos.

hoc titulo En este título, con este título.

homo litteratus Letrado. Si a los jurisconsultos se los llama letrados es porque ellos trabajan con letras, con el idioma, pero los verdaderos letrados son los filólogos, gramáticos, 
lingüistas y letras, quienes tiene como objeto de su estudio el idioma, tanto el autóctono como el de otros países.

humanitas Humanismo, con referencia a las artes y letras, por ser creacio mnes y estudios con el fin del formar el ser humano.

\section{I}

ibidem (ib.) Allí mismo, en el mismo lugar. En el mismo sitio del libro. Se usa para evitar repetir una referencia bibliográfica.

id Los mismos.

id est (i.e, i.d) Esto es, es decir, a saber.

idem Lo mismo. Se emplea para evitar repeticiones. Neutro singular.

idem quod (i.q.) Lo mismo que...

igitur Por lo tanto, por consiguiente.

imitatores, servum pecus Esos imitadores, servil ganado. Refiere Horacio que la imitación ha de ser creativa, pues la imitación por la imitación no tiene razón de ser. Sólo los animales imitan sin saber por qué y sin innovar.

impressum < impressus, - $a$, - um $<$ in primo, -essi, -essum, -ere. Impreso, hacer presión en algo, hacer una marca mediante presión, dejar impreso, imprimir; de la expresión latina imprimere in cera sigillum, imprimir un sello en la cera, de donde la palabra imprenta. Escrito ya impreso.

imprimatur Imprimase. Tal libro puede ser impreso. Autorización eclesiástica oficial para que se imprima un libro que no vaya contra la fe ni las buenas costumbres. Voz pasiva, tercera persona singular del subjuntivo presente.

imprimi potest $=$ imprimatur El libro puede ser impreso. Tal libro tiene permiso para ser impreso.

in absentia (i.a.) En ausencia.

in aeternum Por siempre.

incipit Comienza, inicia. Inicio de un manuscrito o de cualquier impreso.

index Índice.

in dies (in. d.) Diariamente. infra (inf.) Abajo. En la parte inferior de un libro. initio (init.) Al principio, en el inicio (por ejemplo, de un libro).

ignotus (ign.) Desconocido.

(in) illo tempore En aquel tiempo, en aquellos tiempos. Modo usual como inicia la lectura de un pasaje del Evangelio.

in limine (in lim.) En el umbral, en el dintel. In limine belli, en el comienzo de la guerra; in limine mortis, a las puertas de la muerte.

in medias res Llegar al núcleo del asunto que se está tratando, como lo refiere al Ars Poetica de Horacio (65-8 a. Ch.), con referencia a Homero quien había lanzado a su lector en medio del asunto o de la acción.

in memoriam A la memoria de...

in principio (in pr.) En el principio. In principio creavit Deus (Gen.1:1) En el principio creó Dios.

inscriptio, exordium, expositio Normas para redactar documentos oficiales.

(in) statu quo En el estado en que... En una situación invariable.

intelligenti pauca $\mathrm{Al}$ inteligente, poco. A la persona inteligente le bastan pocas palabras para entender.

interpretamentum En un glosario, o diccionario, la parte que explica la palabra por conocerse o lemma.

in transitu (in transit.) En tránsito, de paso.

invenit (inv.) Lo encontró.

iuris Doctor (I. D.) Doctor en derecho.

utriusque Doctor (I.U.D.) Doctor en los dos derechos: el civil y el canónico o eclesiástico.

\section{$\mathbf{L}$}

lapsus Caída, error, equivocación. Participio perfecto del verbo deponente labor, lapsus sum, $l a b i$, caer, de donde, equivocarse.

lapsus calami Error de la pluma. Equivocación inconsciente en el uso de la lengua escrita. En el presente, bien se podría decir lapsus machinae computatoriae, equivocación de la computadora. 
lapsus linguae Error de lengua. Equivocación verbal. Error involuntario en el empleo de la lengua hablada.

lapsus memoriae Error de la memoria, debido a un recuerdo inexacto, defectuoso u olvido.

lato sensu En sentido amplio.

lector benevole Gentil lector. En latín, el sintagma se haya en caso vocativo.

lectori benevolo (L. B.) Al estimado lector. En latín, este sintagma se haya en caso dativo.

legenda Las cosas que deben ser recogidas, leídas. En latín, es un gerundivo en neutro plural, de donde se deriva la palabra "leyenda" en femenino singular.

legum Baccalaureus (LL. B.) Bachiller en leyes.

legum Doctor (LL. D.) Doctor en leyes, jurisprudencia.

libellus Librito, opúsculo, folleto, agenda, diario, carta de petición o de súplica.

liber, libri (1. o lib.) Libro, Libros. En botánica, liber es la capita fina entre la corteza y la madera.

libra (lb.) Libra, peso.

libra pondo Una libra en peso. Libra, medida de capacidad; signo del Zodíaco, palabra esta que se deriva del griego dzon, animal. Pondus, ponderis, peso, en inglés pound. De libra, proviene lira, la moneda de Italia anterior al Euro.

litterae humaniores (Lit. Hum.) Las humanidades, las letras humanas. Por ej., la filología clásica, que más bien pertenece a la rama humanística.

littera scripta manet Lo escrito permanece. De donde el dicho, quod scriptum, scriptum. Lo que está escrito, escrito está. También corresponde a verba volant, scripta manent. El viento se lleva las palabras, pero las escritas permanecen.

litterae scriptae Manuscritos.

litterarum Humaniorum Doctor (L. H. D.) Doctor en Humanidades.

litterarum Doctor (Litt. D.) Doctor en letras.

licentia poetica Licencia poética. Este sintagma, proveniente de Séneca, indica que, por motivos inherentes a un poema, el poeta puede contravenir ciertas leyes gramaticales y retóricas.

licentia vatum Licencia de los poetas. Licencia gramatical o estilística permitida a los poetas para que transgredan normas del idioma.

litteratim Literalmente, al pie de la letra.

loco citato (l. c. o loc. cit. ) En el lugar citado, para no repetir la misma referencia de un pasaje escrito.

loco supra citato (1. s. c.) En el sitio ya citado.

locus amoenus Lugar agradable. En literatura, pintura de un lugar en que alguien se siente bien y a gusto.

locus communis, pl loci communes Lugar(es) comun(es). Tópico, fórmulas y expresiones fijas. Por ejemplo, hacer referencia al año 2000 con el nombre de millennium ya se hizo un locus communis, pues está en boca de todo mundo.

locus sigilli (L.S.) Lugar del sello. Sitio de un documento oficial en donde se ha de estampar el sello.

loquitur (loq.) Se dice. Tercera persona singular del presente indicativo del verbo deponente loquor, -eris, locutus sum, loqui, hablar, decir.

ludus grammaticus vel ludus litterarius Escuela de primeras letras. Ludus es juego y corresponde al griego scholée, ocio constructivo. La escuela como lugar para jugar con las letras y los números.

\section{M}

magister Artium (A. M. = M. A.) Maestro en artes. Título académico universitario entre el bachillerato y el doctorado propio de, por ejemplo, Alemania.

magister (mr, mg) Maestro. Grado académico universitario intermedio entre el bachillerado y el doctorado.

magna cum laude Con gran distinción, en la aprobación de un examen universitario.

maiuscula(s) < maior, mayor. El alfabeto latino se escribía con letras mayúsculas; a partir del Renacimiento Carolingio comienzan a ser usadas las minúsculas. 
manu propria (m.p.) Firmado con el propio puño y letra.

manuscripti (MSS. ) Manuscritos.

manuscriptus (MS.) Manuscrito.

mare magnum Mar grande o gran mar. Desorden, confusión

masculinum (m.) Masculino. Género gamatical.

minuscula $<$ minus, menor. Letra minúscula, de donde la Minuscula Carolina, que comenzó a ser usada, en la Edad Media, en el monasterio francés de Tours, cuando era abad Alcuino de York.

missa $=$ misa. Una elipsis de missa (est), fue enviada...la Eucaristía como último acto litúrgico. El verbo está en perfecto de indicativo, voz pasiva de mitto, -is, missi, missum, mittere, enviar.

medicinae Doctor (M. D.) Doctor en medicina. memorandum, pl. memoranda Lo que debe ser recordado. Recordatorio (gramaticalización). También se usa la abreviación memo- (forma apocopada).

meridies (m., M.) Mediodía.

millennium $<$ mille annum. Milenio. Palabra que se puso de moda, incluso, en documentos, con motivo del año 2000.

minuta Acta pequeña.

modo praescripto (mod. praesc.) Según lo prescrito.

multa paucis Mucho en pocas palabras. Concisión en el escribir. Como lo estipula Horacio: brevis esto! ¡Sea breve!

muta cum liquida Unión de una consonante muda con una líquida.

mutatis mutandis (m.m.) Cambiando lo que debe ser cambiado.

\section{$\mathbf{N}$}

nascuntur poetae, fiunt oratores Los poetas nacen, los oradores, se hacen. La eloquencia como hija del arte, pero la poesía, se trae consigo.

natus (n.) Nacido. ne varietur! ¡Qué no se cambie! ¡No cambiar! neutrum (n.) Neutro. En latín, neuter, -tra- , neutru, ninguno de los dos.

nexus Nexo, conexión, unión, eslabón, interdependencia.

nihil obstat! Nada impide que... Sin ningún impedimento para...se publique tal o cual obra, sobre todo, en el medio ambiente eclesiástico.

nocte (n) En la noche, de noche.

nomina Nombres, nómina, lista.

non ad narrandum, sed ad probandum No para narrar, sino para probar. Quintiliano, retórico latino de Hispania, refiere que la historia se escribe para probar y no para narrar.

non licet (n. l.) No es permitido, no está permitido. La forma infinitiva es licere $>$ licentia.

non liquet (n.l.) No está claro, no está comprobado.

non obstante (non obs.) No obstante, a pesar de...

non plus ultra No más allá de las míticas columnas de Hércules, para no desafiar los peligros del mar, lo cual, por dicha, no fue atendido por Cristóbal Colón.

non nova sed nove Lo que normalmente se hace cuando uno escribe: aporta quizás no ideas nuevas, pero expuestas de manera diferente. Esto es una misma inventio, pero uno locutio et disposto diferentes.

nota bene (n. b. o N. B.) Anote bien, nota, observaciones. Aclaración en algún texto, generalmente, al pie de página.

notandum = memorandum Lo que debe ser notado, recordado.

non sequitur (non seq.) No sigue, no se sigue...

nulla dies sien linea Ningún día sin ninguna línea. ¡Qué no acabe el día sin haber escrito algo! Refiere Plinio, cuya referencia es, más bien, para la pintura.

números romanos básicos: $\mathbf{I}=\mathbf{1} ; \mathbf{V}=5 ; \mathbf{X}=10$; $\mathbf{L}=50 ; \mathbf{C}=100, \mathbf{D}=500 ; \mathbf{M}=1000$. El sistema esencial romano de enumerar, también es muy empleado, sobre todo, en la escritura. 


\section{$\mathbf{O}$}

o tempora, o mores! ¡Oh tiempos aquellos, oh costumbres! En el inicio de Las Catilinarias, Cicerón pondera y compara los buenos tiempos antiguos con los de época, cuando sobresale, por su maldad, Catilina, quien deseaba someter a Roma igni ferroque, a sangre y a fuego. Cicerón lo desenmascaró mediante su arrebatadora elocuencia.

opus magnum Obra maestra.

obiter (ob.) Ocasionalmente.

omissis Asuntos o cosas omitidas.

omni hora (o.h.) En cualquier hora.

omni nocte (o.n.) Cada noche.

opera omnia Todas las obras. Las obras completas de un escritor, compositor, artista...

opus (op.) Obra. En una serie creativa de la música, número de composición en orden temporal. Por ejemplo, La Sinfonía no. 3 (La Eroica de L. v. Beethoven, tiene el opus 55.

Si el sustantivo está sin h- se debe a que está en italiano, "el idioma de la música".

opus citatum (op. cit. u o. c.), opere citato. Obra citada, en la obra citada. Para no repetir el título de una obra ya escrito en una investigación. El primer sintagma está en nominativo, el segundo, en ablativo.

\section{$\mathbf{P}$}

pagina, paginae (p., pag.) Página, páginas. Parte interna de un papiro cortado en una hoja El verbo correspondiente es pango, -is, pepegi (pegi, pexi), -ere, clavar, establecer, fijar, pactar. De la misma etimología es pax,-acis, paz; pactus, pacto.

partes aequales (p.ae.) Partes iguales.

partim (p.) En parte.

passim (pass.) Aquí y allí; acá y allá, por doquier, por todas partes. Se usa en citas bibliográficas.

paucis verbis En pocas palabras (voy a resumir mi conferencia...) per annum (p.a.) Por año, anualmente.

per cent. (p.c., pct.,) Por ciento.

perfecit Lo llevo a cabo, lo ejecutó, lo acabó. El verbo latino es perficio, perfeci, perfectum, perficere.

philosophiae Baccalaureus (Ph. B.) Bachiller en filosofía.

philosophiae Doctor (Ph. D.) Doctor en filosofía. Aqui "filosofía" no tiene el significado común conocido, sino el etimológico de sabiduría.

pinxit (pinx.,pxt.) Lo pintó.

pluralis (pl.) Plural.

pluralis maiestatis Plural majestático. Empleo de los pronombres personales nos y vos, en vez de yo o Ud., por parte de alguna autoridad civil o religiosa o en la escritura de artículos científicos, tesis y libros.

pluralis tantum Solo en plural. Palabras sin singular, pues solo se usan en plural: pantalones, tijeras. En latín: arma, -armorum, las armas; calendae,-arum, las calendas; divitiae, -arumm las riquezas; comitiae, -arumm las elecciones, liberi, -orum, los hijos.

poscriptum (p. s.) Luego de lo que fue escrito. Agregado al final de un escrito.

post Chrstum natum (p.Ch.n.) Después del nacimiento de Jesucristo.

post data (p.d.) Después de lo dado, de lo enviado. Luego de la fecha de una carta o escrito.

post meridiem (p. m.) Pasado meridiano. Después del mediodía.

praesens pro futuro Presente en vez del futuro. Escribir algo en presente de indicativo en vez del futuro.

praesens pro praeterito Presente en lugar del pretérito. Es narrar algo en el "presente histórico". Colón descubre a América en 1492, en vez de descubrió a América

probatus Aprobado en algún examen.

pro et contra El pro y el contra. Notar lo bueno y malo de algo.

pro forma Factura pro forma. 
pro nunc Por ahora.

prospectus Prospecto. El verbo es prospicio, prospexi, prospectum, prospicere, ver, examinar, considerar.

pro tempore (pro tem., p.t.) Temporalmente, interinamente.

proximo (prox., proxm.) En el próximo mes.<smiles>[Co]</smiles>

quadrivium Quadrivio. Las cuatro materias académicas fundamentales del plan de estudios de la Edad Media, en alusión medieval a los Cuatro ríos del Paraíso.

quantum sufficit / quantum suff. (q.s.) $E n$ cuanto baste.

quantum vis (q.v.) Cuanto quieras.

quasi dictum (q.d.) Como si fuese dicho.

qui scribit bis legit Quien escribe, lee dos veces. Este axioma latina indica que se retiene mejor un texto si uno lo escribe.

quod erat demostrandum (q. e. d.) Lo que debía ser demostrado.

quod erat faciendum (q. e. f.) Lo debía tenía ser hecho.

quod est (q. e.) Lo que es.

quod scripsi, scripsi Lo escrito, escrito está.

quosque tanden...? ¿Hasta cuándo? Inicio de la primera Catilinaria de Marco Tulio Cicerón.

\section{$\mathbf{R}$}

repertorium Catálogo, repertorio.

repetitio, mater studiorum La repetición es la base de los estudios.

repitatur Se repita, sea repetido.

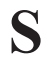

sacrum Romanum Imperium (S. P. I.) El Sacro Imperio Romano.

saeculum, saeculi, saeculo (saec.) Siglo, siglos, en el siglo.

salutem dedit (s.de.) Lo saludó... salutem dicit ( S, sal.) ¡Saludos!

salutem plurimam dedit (s.p. d.) Le envió muchas saludes.

salve! Salvete! / Vale! Valete! ¡Qué esté(n) bien! ¡Saludos!

scilicet (sc., s. c.) A saber, es decir, esto es..

scribendi recte sapere est et principium et fons El principio y fuente para escribir correctamente es saber. (Horacio, justamente, piensa que el conocimiento es la base para escribir bien). La res como base esencial del verbum, pues nadie da lo que no tiene.

scribere iussit amor El deseo de escribir me hizo escribir, refiere Ovidio.

scribere qui nescit, nullum putat esse laborem, Tres digiti scribunt, totum corpusque laborat Quien no sabe escribir, cree que escribir no es ningún trabajo. Tres dedos escriben, pero trabaja todo el cuerpo. (Colofón).

scribitur ad narrandum, non ad probandum Se escribe para narrar algo y no para probarlo; con lo cual Quintiliano hace saber una diferencia entre la historia y la oratoria.

scripsit Lo escribió.

scriptorum chorus omnis amat nemus et fugit urbem $A$ los escritores les gusta huir de la ciudad y refugiarse en los bosques. La paz y la tranquilidad como medio esencial para la producción intelectual, sobre todo, en el campo del arte, refiere Horacio.

scriptura, in qua nulla suscriptio, nullam facit firma Un escrito sin firmar no da ninguna fe ni garantía, reza un principio fundamental del Derecho Romano.

secundum (sec.) Según, de acuerdo con.

secundum artem (sec. art.) De acuerdo con el arte, de acuerdo con las reglas.

secundum legem (sec. leg.) Según la ley, de acuerdo con la ley.

secundum naturam (sec. nat.) Según la naturaleza, naturalmente.

secundum opinionem Según la opinión. 
secundum regulam (sec. reg.) De acuerdo con el reglamento.

senatvs Popvlvsque Romanvs El senado y el pueblo de Roma, escrito, normalmente así: $\mathrm{S}$. P. Q. R. La partícula enclítica -que es lo mismo que et, $\mathrm{y}$.

sensu bono; sensu malo En buen sentido; en mal sentido.

sensu obsceno Con un sentido obsceno de las palabras.

sensu stricto En sentido estricto de las palabras. Sensus, sensus (de la IV. declinación).

sensum non verba considerare debemus Se debe tomar en cuenta el sentido y no las palabras. Este principio se fundamenta en que toda lengua es un código, cuyos signos, las palabras, no siempre van de acuerdo con sus distintas significaciones. Sin embargo, hay que tener cuidado en lo que se expresa.

septuaginta < septem La versión (¿legendaria?) en griego coiné, del Antiguo Testamento de la Bíblia realizada, en Alejandría de Egipto por setentaidós sabios en setentaidós días. Es probable que el rey Ptolomeo Filadelfos (285247) la haya mandado a hacer para que fuera de utilidad en la Biblioteca del Museo.

sequens (seq. s. q., sq.) Siguiente, lo siguiente, lo que sigue. Participio presente del verbo sequor, secutus sum, sequi, seguir. Plural, sequentes.

sequentia (seqq.) Las cosas siguientes, lo siguiente, lo que sigue. Participio neutro plural de sequens, -ntis; convertido en sustantivo femenino singular es sequencia. (gramaticalización).

si opus sit (s.o.s.) Si es necesario.

sic Así. Indicación de que tal o cual palabra se empleó en un texto de alguna manera determinada, pues así se encontraba en el texto del cual se la tomó.

sic in originali Así está en el original.

sic passim Asi por doquier. De esta manera se encuentra en todo el original.

sigla (-orum) Siglas, abreviaturas. signa (S., Sig.) Contraseña. Lo que se escribe en una etiqueta como prescripción médica.

similia, similiter (sim.) Semejante, lo semejante, de manera semejante.

similia similibus curantur Lo semejante cura lo semejante. Lema de la medicina homeopática. sine (s.) Sin.

sine anno (s.a.) Sin año, sin fecha. Cuando, en un libro, no aparece el año de publicación.

sine die (s.d.) Sin día. Indefinidamente.

sine editione (s. e.) Sin edición. Libro sin haber sido editado. Horacio in ars poética, aconseja esto: ...ne praecipitetur editio. Qué no se precipite la edición

sine loco (s.l.) Sin lugar.

sine loco et anno (s.l. a.) Sin lugar ni año (en la edición de un libro).

sine loco, anno, nomine (s.l. a. n.) Sin lugar, año ni nombre (en la edición de un libro).

sine nomine (s. n.) Sin nombre, anónimo.

singularis (sg. sing.) Singular.

singularis tantum Solo en singular. Palabras que carecen de plural como en latín y su correspondiente castellana: gelu, hielo; meridies, meridiano; plebs, la plebe; sanguis, sangre; tussis, tos; ver, primavera...

statim (stat.) Inmediatamente.

stricto sensu En sentido estricto. Sintagma en ablativo singular. El sustantivo es de la IV declinación y el adjetivo, de la II.

stvdivm Vrbis La Universidad de Roma, conocida como "La Sapienza", fundada en 1308 por el papa Bonifacio VIII.

suaviter in modo, fortiter in re Suave en el modo, fuerte en el asunto. Expresión que indica una manera gentil en la forma, pero severo en el fondo, sin claudicar. He aquí una óptima afirmación para un buen docente.

sub anno Debajo del año. Referencia a la entrada en un registro..., luego de haberse puesto la fecha sub audi (sub.) Leer entre líneas.

sub verbo $=$ sub verbo $($ s.v, $\mathrm{s} / \mathrm{v})$. 
sub voce (s .v.) En voz baja, entre nosotros. (En italiano, sotto voce).

sui generis De su mismo género, especie, clase, orden, tipo.

supinus Supino, estar echado boca arriba. Forma verbal poco usada en latín, de la cual se derivan algunos participios.

\section{$\mathbf{T}$}

tabula rasa, tamquam tabula rasa Tabla sin nada escrito. Quedarse uno en blanco, sin nada en la cabeza.

tempore (t.) A tiempo, en tiempo.

terminus ad quem Punto en el tiempo antes de algo.

terminus post quem Punto en el tiempo después de algo.

timeo hominem unius libri Latinismo de Santo Tomás de Aquino con referencia a la persona que tiene un solo libro como su única referencia, el non plus ultra. Tal libro puede ser la Biblia, el Corán, mein Kamp, mi lucha, el Manifiesto comunista, cuya única lectura sin espíritu crítico puede conducir a ser al fundamentalismo y al fanatismo sin importar las nefastas consecuencias

tolle, lege ;Toma y lee!

trívium Trivio. Las tres artes de docencia en la Edad Media: dialéctica gramática y retórica.

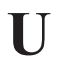

ubi supra (u.s., ut sup.) Como arriba, en el lugar arriba mencionado, según fue escrito arriba de la página, anteriormente. Referencia a algo escrito con anterioridad.

usus scribendi Manera de escribir, estilo.

ut dictum (ut dict.) Según lo dicho, según lo estipulado, de acuerdo con lo manifestado.

ut infra (ut i., ut inf.) Como abajo declarado, según se escribió abajo. Referencia a algo escrito que vendrá posteriormente.

ult. Ultimo El último mes.

\section{V}

vade mecum Ven conmigo. Manual o libro de bolsillo de mucho uso.

vale! Valete! ¡Qué esté(n) bien! ¡Saludos!...

variorum notae Notas con varios comentarios.

verso (v., vo.) En la página de reverso de un documento, libro, cuaderno.

verso / verso folio Página de reverso de un libro, cuaderno, documento.

versus (v., vs.) Contra.

verba sciendi et declarandi Verbos que denotan una actividad intelectual y de declaración, después de los cuales se suele usar, en latín, acusativo con infinitivo

verba volant, scripta manent Las palabras vuelan, lo escrito permanece.

verbatim et literartim Palabra por palabra y letra por letra, exacto.

verbi causa $=$ verbi gratia Por ejemplo .

verbi gratia (v. g., v. gr.) Por ejemplo.

verbum Palabra.

verbum sapienti (verb. sap.) $\mathrm{Al}$ sabio le basta una palabra.

viceversa ( v. v.) Al revés.

vide, videatur (v., vd., vid.) Vea, véase, cf. (confer)

vide ante (v. a.) Ver antes.

vide infra (v. i.) Ver abajo.

vide supra (v. s.) Ver arriba o anteriormente.

vir bonus dicendi peritus Frase de Catón el Viejo dirigida a su hijo en donde le da a entender que el orador es un hombre que sabe expresarse bien pero que también actúa bien en la vida: el talento y la virtud; lo contrario de Adolph Hitler, ducho en sus discursos enardecidos, pero, como él era malo, le causó mucho daño al mundo, por culpa de la misma gente, que, en general, no tuvo espíritu crítico hacia sus palabras.

vir litteratus Hombre de letras, hombre culto.

vixit... annos (v. an.) Vivió...años. 
vulnerant omnes, ultima necat En ciertos templos y públicos europeos, algunos relojes suelen tener esta inscripción, la cual indica una triste realidad: el tiempo inexorablemente se escapa: las campanadas del reloj, y su última campanada te deja tieso en el suelo.

En agradecimiento. para mis compañeros, amigos y alumnos del Departamento de Filología Clásica de la Universidad de Costa Rica. 8, 9 y 10 de Octubre del 2013.

\section{Bibliografía}

Álvar, Manuel; Mariner, Sebastián. (1959). Latinismos. En: Enciclopedia lingüística hispánica. Tomo II: Elementos constitutivos: Fuentes. Consejo Superior de Investigaciones Científicas: Madrid.

Bal, Willy. (1966). Introduction aux études de linguistique romane, avec considération spéciale de la linguistique française. Didier:Paris

Bayet, Jean. (1972). Literatvra latina. Ediciones Ariel: Barcelona.

Blánquez. (1970). Diccionario Español-Latino / Latino-Español. Editorial Ramón Sopena, S. A.: Barcelona.

Bloch, O; Von Wartburg, Walter. (1964). Dictionnaire étymologique de la langue française. Presses Universitaires de Frances: Paris.

Capellanus, Georg. (1990). Sprechen Sie Lateinisch? Moderne Konversation in lateinischer Sprache. Ferd. Dümmler Verlag: Bonn.

Corominas, Joan. (2000). Breve diccionario etimológico de la lengua castellana. Editorial Gredos: Madrid.
Ehrlich, Eugene. (1995). Veni, vidi, vici. Conquer your Enemies, impress your Friends with everyday Latin, Harper Perennial: New York.

Ernout, A.: Meillet, A. (1967). Dictionnaire étymologique de la langue latine. Histoire des mot. Librairie C. Klincksieck: Paris.

Guillén, José. (1963). Gramática latina. Ediciones Sígueme: Salamanca.

Iglesias, Octavio. (1966). De dónde vienen las palabras. Diccionario de etimología. Ediciones temas de hoy, S. A.: Madrid.

Lamer, Hans; Kroh, Paul. (1989). Wörterbuch der Antike. Alfred Kröner Verlag: Stuttgar.

Lapesa, Rafael. (1980). Historia de la lengua española: Editorial Gredos. Madrid.

Lázaro Carreter, Fernando. (1984). Diccionario de términos filológicos. Editorial Gredos: Madrid.

Marchi, Cesare. (1994). Siamo tutti latinisti. Tutte le parole latine che usiamo senza saperlo.RCS Rizzoli S.p.A.: Milano.

Martin, F. (1976). Les mots latin. Hachette: Paris.

Martínez de Sousa, José. (1995). Diccionario de lexicografía práctica. Biblograf. S. A.: Barcelona.

Prampolini, Santiago. (1955). Historia universal de la literatura. III: ...latina medieval... Unión Tipográfica Editorial Hispano Americana (UTEHA): Buenos Aires.

Quirós Rodríguez, Manuel Antonio. (2000). El latín y las lenguas romances. Editorial de la Universidad de Costa Rica: San José. 
Quirós Rodríguez, Manuel Antonio. (S. d.) Latinismos de la filosofía, ciencias, artes y letras.

Real Academia Española. (1970). Diccionario de la lengua española. Madrid.

Reichert, Heinrich G. (S. d.) Unvergänglich lateinische Spruchweisheist. Urban und human. Panorama Verlag: Wiesbaden.

Rónai Paulo. (1980). Nao perca o seu LATIM. Editora Nova Fronteira: Rio de Janeiro.

Saínz de Robles, Federico Carlos. (1972). Ensayo de un diccionario de Literatura. Tomo I: términos, conceptos, "ismos literarios". Aguilar: Madrid.
Segura Munguía, Santiago. (1985). Diccionario etimológico latino-español. Ediciones Generales ANAYA: Madrid.

Segura Munguía, Santiago. (1987). Latín $2^{\circ}$. Ediciones ANAYA, S. A.: Madrid.

Sellner, Alfred. (S. d.) Latein im Alltag. Sentenzen, Sprichwörter, Phrasen, Redewendungen, Formelzitante. VmaVerlag: Wiesbaden.

Siegel P., Conrad. (1960). Gramática latina. Editorial Guadalupe: Buenos Aires.

Stone, Jon R. (1966). Latin for the Illiterati: New York and London. Routledge.

Tagliavini, Carlo. (1973). Orígenes de las lenguas neolatinas: Fondo de Cultura Económica. México. 